\title{
FREQUENCY OF ELEVATED BLOOD PRESSURE ASSOCIATED WITH LIFESTYLE CHOICES AMONG SCHOOL GOING ADOLESCENTS IN KARACHI: A CROSS SECTIONAL SURVEY
}

\section{Felicianus Anthony Pereira, Jumana Abdul Qadir, Sajida Kamran PT}

\begin{abstract}
Background: Studies have suggested that atherosclerotic changes take place in the body since childhood due to altered dietary patterns and sedentary lifestyle. It is critical to identify gap areas and update current literature to produce effective changes in our lifestyle.
\end{abstract}

Study design: A cross-sectional survey conducted among school going adolescents in Karachi.

Methods: A cross sectional study was performed in three different schools of Karachi. A sample size of 288 was drawn through nonprobability, purposive sampling technique. Students were given a questionnaire comprising of questions regarding their physical activity levels, dietary patterns and knowledge regarding blood pressure. Blood pressure and Body Mass Index data was also recorded.

Results: Mean age of participants was $14.10 \pm 1.097$. Of the 288 students that participated in this study (122 boys and 166 girls), 227 were normal for hypertension status (93 boys and 134 girls), 27 were pre-hypertensive ( 7 boys and 20 girls), and 34 were hypertensive (22 boys and 12 girls). Mean systolic blood pressure was $112.73 \pm 13.49$, and mean diastolic blood pressure was 71.25 
\pm 13.03. Awareness among participants was high regarding hypertension being linked to the foods they consumed $(62.8 \%)$.

Conclusion: Our study did not show strong correlation between physical activity and dietary patterns, with status of hypertension. Screening programs should be conducted in schools to monitor blood pressure and body mass index. High risk groups should be approached and advised for lifestyle modification.

Keywords: hypertension, adolescents, life style

\section{Introduction}

With a worldwide prevalence of $40.8 \%$, hypertension (HTN) is a rapidly increasing public health problem. It is now recognized as one of the major risk factors for cardiac, cerebrovascular and chronic kidney disease. ${ }^{1}$ Every year, elevated blood pressure leads to $54 \%$ of strokes, $47 \%$ of ischemic heart disease (IHD) and 7.6 million premature deaths. ${ }^{2}$ There is limited updated information on the prevalence of hypertension in Pakistan. ${ }^{1}$ In recent times, HTN has been started to be acknowledged as an important pediatric crisis. ${ }^{3}$ The definition of "normal blood pressure" is given as Systolic Blood Pressure (SBP) and Diastolic Blood Pressure (DBP) values <90th percentile according to age, sex and height. "Prehypertension" or elevated blood pressure for adolescents is defined as $\mathrm{BP} \geq 120 / 80 \mathrm{~mm} \mathrm{Hg}$ to $<95$ th percentile, or $\geq 90$ th and $<95$ th percentile, whichever was lower. ${ }^{4}$ Evidence documents that lifestyle choices in childhood associated with risk factors which include dietary habits and physical activity levels contribute to elevated blood pressure in children. ${ }^{5}$ Furthermore, early origin of risk factors during adolescence and death due to IHD is also 
increasing. However, knowledge regarding this growing epidemic and its high prevalence is deficient among adolescents. ${ }^{2}$

A survey conducted by the World Health Organization (WHO) in 2010 revealed that $81 \%$ of youths between ages of $11-17$ were not sufficiently physically active. Girls performed fewer physical activities than boys ( $84 \%$ vs. $78 \%$ ). WHO claims that sedentary behavior at home contributes to the low levels of physical activity. Similarly, rise in the use of passive modes of transportation is also responsible for insufficient physical activity. ${ }^{6}$

Dietary intake characteristics like; frequency of eating, portion sizes, energy density, high fat, sodas and sugar intake contribute to altered dietary patterns. ${ }^{7}$ Pathological studies show that there is a positive correlation between atherosclerotic lesions and risk factors such as low density lipoprotein cholesterol, triglyceride, SBP \& DBP, body mass index (BMI), and cigarette smoking. ${ }^{5}$ Hence, it is important to evaluate diet for these characteristics in adolescence because it predicts dietary intake in adult life which can thereby cause a risk of chronic diseases. ${ }^{7}$

The purpose of this research was to assess the frequency of elevated blood pressure associated with lifestyle choice in school going adolescents and assess awareness of the modifiable risk factors.

With rate of mortality due to non-communicable diseases rising to 52 million by 2030 it is crucial for our present generation of adolescents to be aware of elevated blood pressure and their relative lifestyle. $^{2}$

According to author's knowledge, elevated blood pressure in adolescents is under reported in our part of the world. ${ }^{8}$ Two major contributing factors are: altered dietary patterns due to ease of 
access to fast food, ${ }^{9}$ and increased screen time leading to sedentary lifestyle. $^{7}$

\section{Methods}

Permission to conduct this study was obtained from Institute of Physical Medicine \& Rehabilitation, Dow University of Health Sciences. (Reference no. IPM\&R/DUHS-17/061)

The cross-sectional survey was conducted on children aged 13 to 16 and enrolled in public and private schools in Karachi, Pakistan. It was performed in compliance with declaration of Helsinki. Principals, teachers and students were briefed about the study. They were explained about the purpose of the study and were assured strict confidentiality. Consent was obtained from parents, as participants in the study were below legal age. Children, teachers, and parents (through consent forms) were informed of the procedure of the study. Sample size was calculated at 282 with confidence interval of $95 \%$ using OpenEpi version 3.01. Data was obtained via a self-design questionnaire.

Blood pressure was measured using a mercury sphygmomanometer (Certeza Desk Type CR-2001). Children were in a calm environment before readings were taken. Appropriate cuff size was used during the research. Blood pressure measurements were taken with the arm extended over the table, at the level of the heart. ${ }^{10}$

Two readings were taken with 5 minutes' interval between each reading, and the average was calculated. ${ }^{10}$ Classification of $\mathrm{BP}$ percentiles was determined using normative tables obtained from National Health and Nutrition Examination Survey data. The 95th 
percentile was used as a measure of elevated blood pressure for the adolescents' gender, height and weight.

Weight was measured using an electronic weighing scale (Senior Model DB-6020 - accurate to $0.1 \mathrm{~kg}$ ). Children were weighed wearing light clothes and no shoes. Standing height was measured with shoes removed and the child facing away from the wall, with the heels, buttocks, shoulders and head touching the wall and the child looking ahead and the external auditory meatus and lower margin of the orbit aligned horizontally. ${ }^{2}$ Height was measured using a tape measure (accurate to $\pm 1 / 2 \mathrm{~cm}$ ). Measurements were recorded between 8:30 a.m. and 11:00 a.m. ${ }^{11}$ Weight and height were converted to metric measurements to determine the BMI, which is calculated by weight $(\mathrm{kg})$ divided by height squared $\left(\mathrm{m}^{2}\right)$.

\section{Results}

Children included in the study were between 13 to 16 years of age. Mean age of participants was $14.10 \pm 1.097$. Of the 288 students that participated in this study, 27 were pre- hypertensive, and 34 were hypertensive (9.4\% and $11.8 \%$ respectively). (Table 1) Gender wise distribution of status of HTN is shown in Figure 1. Mean SBP was $112.73 \pm 13.49$, and mean DBP was $71.25 \pm 13.03$.

The association found between status of HTN and status of BMI was statistically significant ( $p$ value $=0.000$ ). (Table 2) Cross tabulation of status of hypertension with frequency of sitting and lying down showed no statistical significance ( $p$-value=0.878). Statistical significance ( $\mathrm{p}$-value $=0.001)$ was also noted between cell phone usage and status of hypertension. Weak association ( $\mathrm{p}$ value=0.936) between cigarette smoking and status of hypertension was noted in this study. 285 participants did not 
smoke at all. 2 participants smoked to a moderate extent; both had normal HTN status. Statistical significance (p-value=0.007) was found between consummation of soft drinks, and the status of hypertension (Table 3)

\section{Tables}

\begin{tabular}{|c|c|c|}
\cline { 2 - 3 } \multicolumn{1}{c|}{} & Frequency & Percent \\
\hline Status of HTN & \multicolumn{2}{c|}{} \\
\hline Normal & 227 & 78.8 \\
\hline Pre-hypertensive & 27 & 9.4 \\
\hline Hypertensive & 34 & 11.8 \\
\hline Total & 288 & 100 \\
\hline
\end{tabular}

Table 1: status of HTN

\begin{tabular}{|c|l|l|l|l|}
\hline \multicolumn{1}{|c|}{$\begin{array}{l}\text { Status of } \\
\begin{array}{l}\text { Status } \\
\text { of } \\
\text { BMI }\end{array}\end{array}$} & Pormal & Pre-hypertensive & Hypertensive & Total \\
\hline Underweight & 113 & & & \\
\hline Normal & 95 & 11 & 10 & 134 \\
\hline Overweight & 17 & 13 & 11 & 119 \\
\hline Obese grade I & 2 & 2 & 10 & 28 \\
\hline Total & 227 & 27 & 3 & 7 \\
\hline
\end{tabular}

Table 2: association of status of BMI with status of HTN 


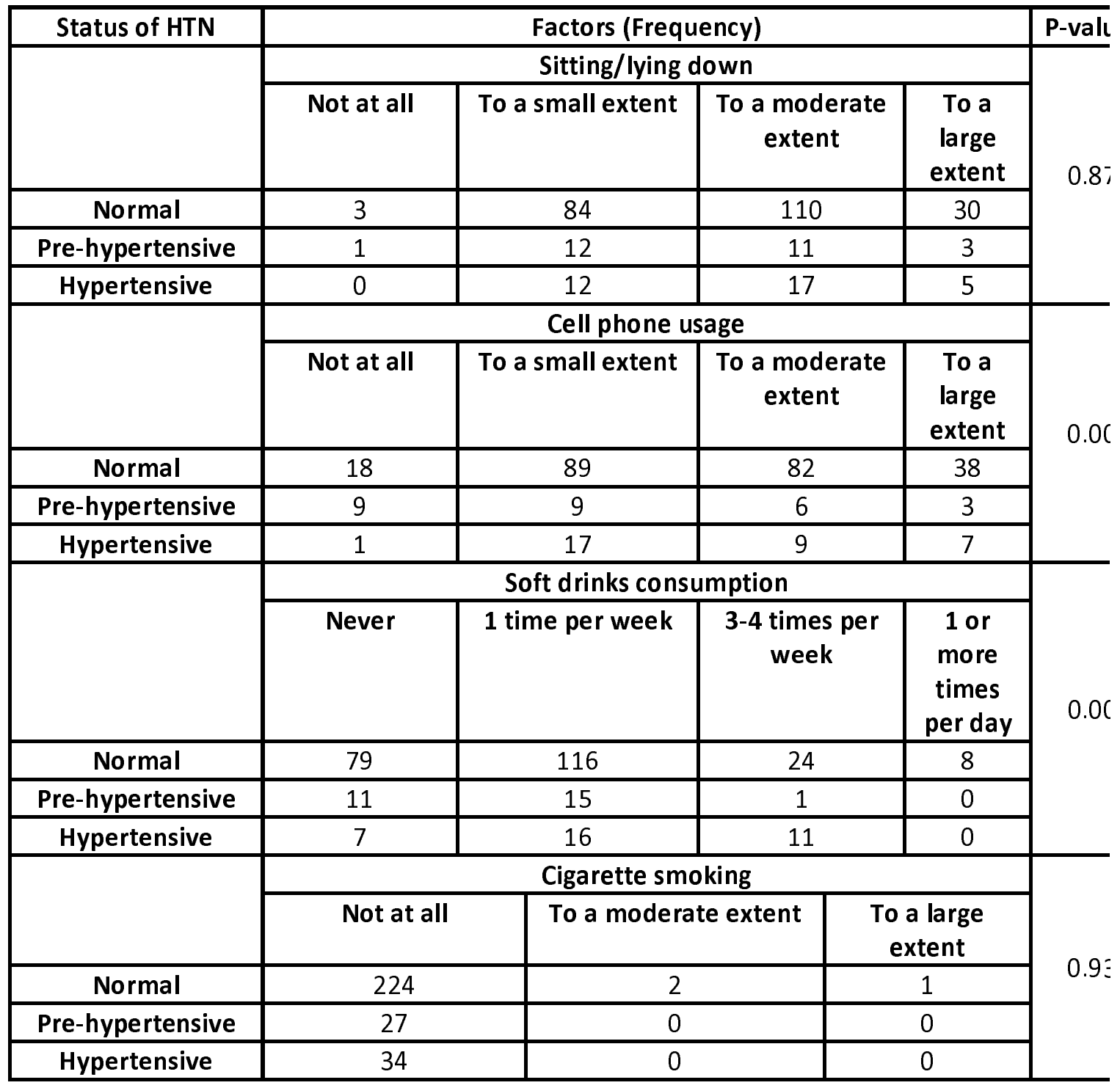

Table 3: association of status of hypertension with sitting/lying down, cell phone usage, soft drinks consumption and cigarette smoking 
medRxiv preprint doi: https://doi.org/10.1101/2020.05.11.20098822; this version posted May 18, 2020. The copyright holder for this preprint (which was not certified by peer review) is the author/funder, who has granted medRxiv a license to display the preprint in perpetuity.

It is made available under a CC-BY 4.0 International license.

\section{Figures}

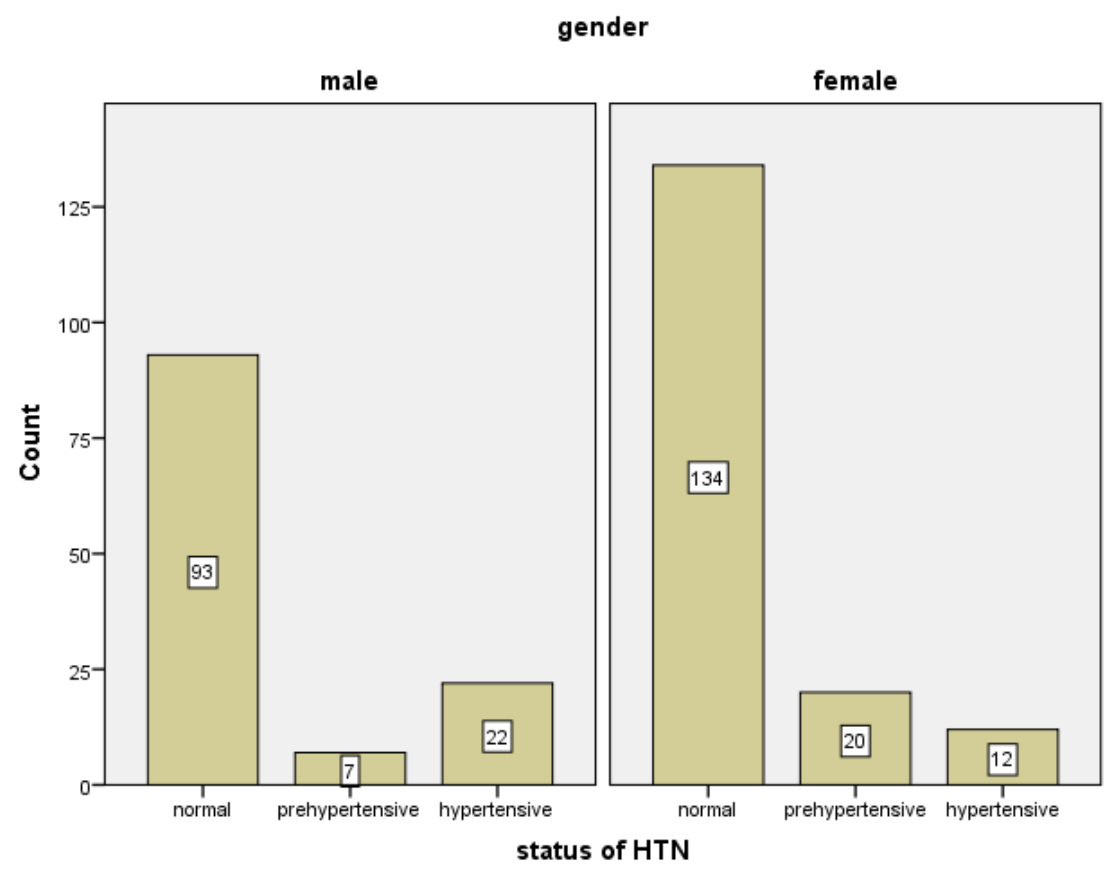

\section{Discussion}

In this study the prevalence of BP > 95th percentile is $11.81 \%$, BP between 90th and 95th percentile is $9.38 \%$. These are quite similar 
with the results of previous studies. ${ }^{12} 13$ Various studies in different parts of the world report a prevalence ranging from $0.46 \%$ to $21.8 \%$. The reason for this might be due to the difference in the study group's age and ethnicity. ${ }^{14}$ It is worth mentioning that the difference in number of times the measurements were taken reduced the prevalence from $13 \%$ to $1 \%$ between the first and third visits. $^{15}$

In this study, obesity, altered food habits and physical inactivity are three risk factors that have been found to be independently associated with high BP. Results of a study conducted by Cinteza and Balgradean and Rahman et al. support the association between obesity and elevated blood pressure. ${ }^{16}$ A study conducted on Pakistani students had the same findings. ${ }^{17}$ Another study suggested that there is a shift in the arterial pressure control mechanism of diuresis and naturesis due to activation of sympathetic nervous system, in obese adolescents which ultimately leads to higher BP levels. ${ }^{18}$ In our study no statistically significant association was noted between consumption of junk food and that status of HTN. Similar results were found in a study conducted by Jasmine s sunder et al. ${ }^{19}$ However, in a study conducted by Sentamizh Prasad et al. there was a significant statistical association between the former two variables. ${ }^{2}$ As with the results of other studies, our research indicated strong statistical significance between increased screen time and elevated blood

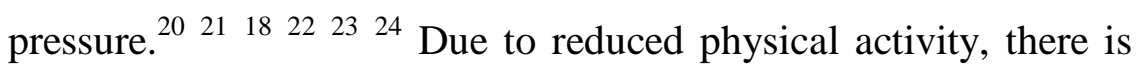
dysregulation of body weight, insulin usage and indirectly blood lipids, glucose and clotting factors get deranged, altering the blood vessels and thereby altering blood pressure. ${ }^{25}$

Knowledge about HTN was high among participants. 89.2\% had been informed by a teacher or a guardian about BP; this contrasts 
with the findings of Prasad et al study, where adolescents had a poor understanding of knowledge of BP. ${ }^{2}$ Majority of participants $(62.8 \%)$ were aware of BP being linked to the foods they consumed.

Limitations of our research were that BP measurements were taken twice; assessment of dietary patterns was done via questionnaire, based on responses from participant's memory, which may be subject to recall bias. No observation was done to assess levels of physical activity. Also, a stratified sampling technique would have been more appropriate, as the participants in our study were from Dawoodi Bohra community, and is not a complete representation of the different ethnic groups of adolescents in the country.

Informative sessions can be conducted in schools to inform children and parents about relation between obesity and hypertension. Intervention strategies should be implemented at national level, such as the banning of soft drinks at schools by the Punjab government ${ }^{1}$ to reduce the chances of cardiovascular diseases developing later in life.

\section{Conclusion}

We conclude that there is no strong correlation between physical activity and dietary patterns with status of hypertension among adolescents. However, screening programs should be conducted in schools to monitor blood pressure and BMI. Ultimately, high risk groups should be approached and advised for lifestyle modification.

\section{Acknowledgement}

The authors would like to acknowledge all school children and their caregivers for their co-operation in the study. 


\section{Conflict of interest}

The authors report no conflict of interest.

\section{Funding}

No funding was obtained for this study.

\section{References}

1. Salman T. Shafi TS. A survey of hypertension prevalence, awareness, treatment, and control in health screening camps of rural central Punjab, Pakistan. Journal of Epidemiology and Global Health. 2017; 7.

2. Senthamizh Prasad JM, Anand Kumar Srivastava, and Prabhaker Mishra. Elevated blood pressure and its associated risk factors among adolescents of a North Indian City - A cross-sectional study. Indian Journal of Community Medicine. 2017; 42.

3. Alejandro Díaz MDaaLC. High blood pressure in school children and adolescents in Argentina over the past 25 years: A systematic review of observational studies. Arch Argent Pediatr. 2017; 115.

4. Flynn JT KD, Baker-Smith CM. Clinical

Practice Guideline for Screening and Management of High

Blood Pressure in Children and Adolescents. Pediatrics. 2017.

5. Rae-Ellen W. Kavey SRD, Ronald M. Lauer, Dianne L. Atkins, Laura L. Hayman and Kathryn Taubert. American Heart Association Guidelines for Primary Prevention of Atherosclerotic Cardiovascular Disease Beginning in Childhood. American Heart Association 2003; 107. 6. Organization. WH. Physical activity. 2017 [cited 201728 August]; Available from: http://www.who.int/mediacentre/factsheets/fs385/en/ 7. Anna Winkvist1* BH, Jeong-Lim Kim2, Ingegerd Johansson3, Kjell Torén2, Jonas Brisman2 and Heléne Bertéus Forslund. Dietary intake, leisure time activities and obesity among adolescents in Western Sweden: a cross-sectional study. Nutrition Journal. 2016; 15.

8. Abdul Ghaffar KSR, Monica Singhi Burden of non-communicable diseases in South Asia. BMJ. 2004; 328:807-10.

9. J Jiao, * A V Moudon, S Y Kim, P M Hurvitz, and A Drewnowski. Health Implications of Adults' Eating at and Living near Fast Food or Quick Service Restaurants. Nutr Diabetes 2015; 5.

10. Thomas G. Pickering JEH, Lawrence J. Appel, Bonita E. Falkner, John Graves, Martha N. Hill, Daniel W. Jones, Theodore Kurtz, Sheldon G. Sheps, and Edward J. Roccella. Recommendations for Blood Pressure 
medRxiv preprint doi: https://doi.org/10.1101/2020.05.11.20098822; this version posted May 18, 2020. The copyright holder for this preprint (which was not certified by peer review) is the author/funder, who has granted medRxiv a license to display the preprint in perpetuity.

It is made available under a CC-BY 4.0 International license .

Measurement in Humans and Experimental Animals. American Heart Association. 2004; 45.

11. de Almeida MMS, Guimaraes RA, Jardim P, Sousa ALL, de Souza MM. Association between arterial hypertension and nutritional status in adolescents from Goiania, Goias, Brazil. PloS one. 2017; 12:e0188782.

12. Haiquan $\mathrm{Xu} X \mathrm{H}, 1$ Qian Zhang, 1 Songming Du, 1 Hongyun Fang, 1 Ying Li, 2 Jun Ma, 3 Tingyu Li, 4 Lin Du, 5 Hongwei Guo, 6 Guifa Xu, 7 and Ailing Liu $1, *$. The Association of Hypertension with Obesity and Metabolic Abnormalities among Chinese Children. International Journal of Hypertension. 2011.

13. Vânia Ames Schommer SMB, 1 Cláudia Ciceri Cesa,1 Rosemary Oliveira, 1 Anelise Damiani Silva,2 and Lucia Campos Pellanda1,2. Excess Weight, Anthropometric Variables and Blood Pressure in Schoolchildren aged 10 to 18 years. Arquivos brasileiros de cardiologia. 2014.

14. Bancalari R DC, Martínez-Aguayo A, Aglony M, Zamorano J, Cerda V,. Prevalence of hypertension in school age children and its association with obesity. REv Med Chil. 2011; 139.

15. Lauer RM ML, Clarke WR. Tracking of blood pressure during childhood: The Muscatine study. Clin Exp Hypertens. 1986; 8.

16. Cinteza E BM. Hypertension in romanian children and adolescents: A cross-sectional survey. Maedica (Buchar) 2013; 8.

17. Arshalooz Jamila Rahman FNQ, Sohail Ashraf, Zubair Ali Khowaja, Shafaq Binte Tariq, Hira Naeem. Prevalence of hypertension in healthy school children in Pakistan and its relationship with body mass index, proteinuria and hematuria. Saudi Journal of Kidney Diseases and Transplantation. 2013; 24:408-12.

18. Ostrowska-Nawarycz L NT. Prevalence of excessive body weight and high blood pressure in children and adolescents in the city of Lodz. Kardiol Pol. 2007; 65:1079-87.

19. Sundar JS, Adaikalam J, Parameswari S, Valarmarthi S, Kalpana $S$, Shantharam D. Prevalence and determinants of hypertension among urban school children in the age group of 13-17 years in, Chennai, Tamilnadu. Epidemiology. 2013; 3:2161-1165.1000130.

20. Sumit Kar BK. Fast foods and physical inactivity are risk factors

for obesity and hypertension among adolescent

school children in east district of Sikkim, India. Journal of Natural Science, Biology and Medicine. 2017; 6.

21. JS S. Prevalence and determinants of hypertension among urban school children in the age group of 13-17 years in, Chennai, Tamilnadu. Epidemiology. 2013; 3:1-5.

22. Gupta AK AA. Childhood obesity and hypertension. . Indian Pediatr. 1990; 27:333-7.

23. Carter MA TM. Do childhood excess weight and family food insecurity share common risk factors in the local environment? An examination using a Quebec birth cohort. . Applied Physiology, Nutrition, and Metabolism. 2014; 39. 
medRxiv preprint doi: https://doi.org/10.1101/2020.05.11.20098822; this version posted May 18, 2020. The copyright holder for this preprint (which was not certified by peer review) is the author/funder, who has granted medRxiv a license to display the preprint in perpetuity.

It is made available under a CC-BY 4.0 International license.

24. Musaiger AO A-MM, Zagzoog N. Association between food intake frequency and obesity among adolescent girls in Saudi Arabia. Int J Adolesc Med Health. 2014; 26:145-7.

25. Federation WH. [cited 2016 feb 26]; Available from:

http://www.world-heart-federation.org/cardiovascular-

health/cardiovascular-disease-risk-factors/physical-inactivity. 